\title{
Consistency and reliability of the auditory vocal hallucination rating scale (AVHRS)
}

Received 28 September 2011; Revised 21 January 2012; Accepted 29 January 2012; First published online 13 March 2012

Key words: Auditory hallucinations, interview, psychometrics, research.

\section{Dear Editor}

Assessing characteristics of auditory vocal hallucinations $(\mathrm{AVH})$ is a key issue in psychiatric clinical practice and research. Recently, a review of assessment tools for AVH has been published (Ratcliff et al. 2011), describing two structured interviews and eight selfreport instruments. Meanwhile, the auditory vocal hallucinations rating scale (AVHRS) (Jenner \& Van de Willige, 2002) developed since 1996 has been used in adolescent and adult patient research (Van de Willige et al. 1996; Jenner \& Van de Willige, 2001) and in research on non-clinical children (Bartels-Velthuis et al. 2010, 2011, 2012). We examined the consistency, the inter-rater reliability and the discriminative power of the AVHRS.

\section{Methods}

\section{Instruments}

\section{Development of the AVHRS}

At the voices outpatient department (VOPD), the auditory hallucination rating scale (AHRS) was developed to examine the effectiveness of therapy (Van de Willige et al. 1996). Items were derived from clinical practice, from symptom characteristics formulated in the Schedules for Clinical Assessment in Neuropsychiatry (SCAN) (Wing et al. 1990) and from DSM-IV (American Psychiatric Association, 1994).

In a population-based survey among 7- and 8-yearold children assessing prevalence and characteristics of auditory vocal hallucinations (AVH) (BartelsVelthuis et al. 2010), the initial AHRS was combined with items of the auditory hallucinations subscale (AHS) of the psychotic symptom rating scale PSYRATS (Haddock et al. 1999), resulting in the auditory vocal hallucinations rating scale (AVHRS) (Jenner \& Van de Willige, 2002). In addition, three items were

* Address for correspondence: Agna Bartels, PhD, University Medical Center Groningen, University Center for Psychiatry, PO Box 30.001 (CC72), 9700 RB Groningen, The Netherlands.

(Email: a.a.bartels@umcg.nl) added: (i) voices talking separately or simultaneously, guided by the observations that patients' suffering increases when voices are talking simultaneously; (ii) hypnagogic and/or hypnopompic hallucinations $(\mathrm{HHH})$, which might be regarded as non-pathological and not uncommon in accompanying narcolepsy (DSM-IV) (American Psychiatric Association, 1994), but still might elicit anxiety and distress; (iii) form of address of voices (talking in the first, second or third person), as particularly third person voices (talking about the patient and/or commenting on patient's activities, two of Schneider's first rank symptoms (Schneider, 1957)) are related to schizophrenic disorders.

\section{Content of the AVHRS}

The AVHRS is a structured 16-item interview, to evaluate patient's experiences during a predetermined period (e.g. past month, past year). Each item consists of a compulsory question, followed by optional support questions. Items are scored on a 5-point scale, ordered in increasing severity, facilitating calculation of a severity score. For experienced therapists and researchers, no training in administering the AVHRS is required. Duration of the interview is around $20 \mathrm{~min}$.

\section{Subjects}

Data from two samples were analysed: (1) adult patients $(n=62)$, who were questioned about their voices in the past month as part of the regular intake at the VOPD. Forty-two patients (68\%) had a diagnosis in the schizophrenic spectrum, $11(18 \%)$ had a mood disorder with psychotic features, nine patients had various diagnoses (e.g. borderline personality disorder, dissociative disorder); (2) non-clinical children with auditory hallucinations $(n=347)$ from a population-based survey of 3870 children, aged 7 and 8 years (Bartels-Velthuis et al. 2010). AVHRS items and scores of the two samples are presented in Table 1. Characteristics of participants are presented in Table 2. 
Table 1. The AVHRS: items and scores of different samples in percentages

\begin{tabular}{|c|c|c|c|}
\hline & $\begin{array}{l}\text { Items and item categories } \\
\text { Assessment period }\end{array}$ & $\begin{array}{l}\text { Adult patients }(n=62) \\
\text { Past month }\end{array}$ & $\begin{array}{l}\text { 7-/8-year-old children }(n=347) \\
\text { Past year }\end{array}$ \\
\hline 1a & Number of voices mean (S.D.; range) & $\begin{array}{l}5.9(6.4 ; 1-30) \\
\%^{\mathrm{a}}\end{array}$ & $\begin{array}{l}1.7(1.6 ; 1-10) \\
\%^{\mathrm{a}}\end{array}$ \\
\hline \multirow[t]{4}{*}{$1 b$} & Separately or simultaneously & & \\
\hline & Always one voice & 16 & 70 \\
\hline & Several voices, speaking separately & 37 & 18 \\
\hline & Several voices, (occasionally) speaking simultaneously & 47 & 12 \\
\hline \multirow[t]{5}{*}{2} & Hypnagogic and/or hypnopompic voices ${ }^{\mathrm{b}}$ & & \\
\hline & Only voices when falling asleep & 0 & \\
\hline & Only voices during waking up & 0 & \\
\hline & Voices when falling asleep and during waking up & 0 & \\
\hline & Voices occur at all times & 100 & \\
\hline \multirow[t]{5}{*}{3} & Frequency & & \\
\hline & Once a week or less & 6 & 70 \\
\hline & At least once a day & 32 & 27 \\
\hline & At least once an hour & 16 & 1 \\
\hline & Continuously & 45 & 2 \\
\hline \multirow[t]{5}{*}{4} & Duration & & \\
\hline & A few seconds & 7 & 66 \\
\hline & A few minutes & 29 & 29 \\
\hline & At least one hour & 8 & 3 \\
\hline & Continuously & 57 & 2 \\
\hline \multirow[t]{5}{*}{5} & Localization & & \\
\hline & Inside the head & 44 & 55 \\
\hline & Inside and outside the head & 20 & 21 \\
\hline & Outside the head, near the ears & 16 & 6 \\
\hline & Outside the head, further away & 20 & 17 \\
\hline \multirow[t]{5}{*}{6} & Loudness & & \\
\hline & Whispering & 21 & 66 \\
\hline & Normal voice & 34 & 25 \\
\hline & Louder than normal voice & 7 & 7 \\
\hline & Shouting or screaming & 39 & 3 \\
\hline \multirow[t]{6}{*}{7} & Attribution of origin & & \\
\hline & Internal only & 28 & 50 \\
\hline & Mainly internal & 30 & 7 \\
\hline & Mainly external & 25 & 5 \\
\hline & External only & 17 & 12 \\
\hline & No idea & 0 & 27 \\
\hline \multirow[t]{6}{*}{8} & Negative content & & \\
\hline & Never unpleasant & 3 & 44 \\
\hline & Only occasionally unpleasant & 7 & 21 \\
\hline & More than occasionally but less than $50 \%$ unpleasant & 15 & 14 \\
\hline & $\geq 50 \%$ unpleasant & 37 & 12 \\
\hline & Always unpleasant & 39 & 10 \\
\hline \multirow[t]{6}{*}{9} & Severity of negative content & & \\
\hline & Not unpleasant & 3 & 53 \\
\hline & Unpleasant, but not about patient/family & 8 & 14 \\
\hline & Unpleasant, about behaviour of patient/family & 7 & 12 \\
\hline & Unpleasant, about patient/family themselves & 24 & 16 \\
\hline & Threatening commands or orders & 58 & 5 \\
\hline \multirow[t]{4}{*}{10} & Frequency of distress or suffering & & \\
\hline & Never & 5 & 58 \\
\hline & Sometimes & 19 & 22 \\
\hline & Half of the time & 15 & 5 \\
\hline
\end{tabular}


Table 1. Continued

\begin{tabular}{|c|c|c|c|}
\hline & $\begin{array}{l}\text { Items and item categories } \\
\text { Assessment period }\end{array}$ & $\begin{array}{l}\text { Adult patients }(n=62) \\
\text { Past month }\end{array}$ & $\begin{array}{l}\text { 7-/8-year-old children }(n=347) \\
\text { Past year }\end{array}$ \\
\hline & Most of the time & 37 & 11 \\
\hline & Always & 24 & 4 \\
\hline \multirow[t]{6}{*}{11} & Intensity of distress or suffering & & \\
\hline & None & 7 & 63 \\
\hline & Some & 16 & 18 \\
\hline & Serious & 19 & 11 \\
\hline & Severe & 37 & 7 \\
\hline & Extreme & 21 & 1 \\
\hline \multirow[t]{6}{*}{12} & Interference with daily functioning & & \\
\hline & None & 3 & 71 \\
\hline & Limited & 29 & 27 \\
\hline & Moderate & 26 & 1 \\
\hline & Severe & 23 & 1 \\
\hline & Complete interference (hospitalization) & 19 & 1 \\
\hline \multirow[t]{6}{*}{13} & Control over voices & & \\
\hline & Full control & 3 & 16 \\
\hline & Some control most of the time & 27 & 12 \\
\hline & Some control half of the time & 10 & 3 \\
\hline & Some control occasionally & 37 & 9 \\
\hline & No control & 23 & 61 \\
\hline \multirow[t]{6}{*}{14} & Anxiety & & \\
\hline & Never & 16 & 53 \\
\hline & Hardly ever & 18 & 13 \\
\hline & Sometimes & 20 & 27 \\
\hline & Most of the time & 10 & 6 \\
\hline & At times completely in panic & 36 & 1 \\
\hline \multirow[t]{6}{*}{15} & Interference with thinking & & \\
\hline & Never & 15 & 44 \\
\hline & Hardly ever & 11 & 12 \\
\hline & Sometimes & 36 & 25 \\
\hline & Most of the time & 32 & 12 \\
\hline & Always & 7 & 7 \\
\hline \multirow[t]{4}{*}{16} & Form of address ${ }^{c}$ & & \\
\hline & 16.1: first person voices present & 30 & 31 \\
\hline & 16.2: second person voices present & 92 & 66 \\
\hline & 16.3: third person voices present & 53 & 9 \\
\hline \multicolumn{2}{|c|}{ Severity score mean (S.D.; range) } & $7.7(3.6 ; 0-13)$ & $2.1(1.9 ; 0-10)$ \\
\hline
\end{tabular}

${ }^{a}$ Due to rounding, percentages may not add up to 100 .

${ }^{\mathrm{b}}$ This item was discarded in the children study.

cFirst, second and third person voices are not mutually exclusive.

\section{Analysis}

To establish inter-rater agreement, 23 successive interviews from sample 1 were observed by four raters. In sample 2, the Dutch Central Committee on Research involving Human Subjects did not allow inter-rater agreement assessments. Thus, each of the eight interviewers of sample 2 rated five DVD-recorded interviews of VOPD patients. Inter-rater agreement was analysed with Agree-6 for Windows (Popping, 1983).
Measure of agreement was (Cohen's) kappa (ranging from ' 0 ' $=$ 'no agreement' to ' 1 ' = 'perfect agreement'). Linear weighted kappas were used, as item responses are ordered in increasing severity, except for the items on $\mathrm{HHH}$ and localization of voices: the main purpose of the item on $\mathrm{HHH}$ is to differentiate between $\mathrm{HHH}$ and more genuine AVH and the item 'localization of AVH' (hearing voices inside or outside the head) was shown to have no intrinsic effects on severity (Copolov et al. 2004). 
Table 2. Characteristics of participants and psychometric outcomes of the AVHRS

\begin{tabular}{|c|c|c|c|c|c|c|c|c|}
\hline \multirow[b]{2}{*}{ Characteristics } & \multicolumn{4}{|c|}{ Sample 1} & \multicolumn{2}{|l|}{ Sample 2} & \multicolumn{2}{|c|}{$\begin{array}{l}\text { Five-year follow-up study } \\
\text { of Sample } 2\end{array}$} \\
\hline & \multicolumn{2}{|c|}{ Patients VOPD } & \multicolumn{2}{|c|}{$\begin{array}{l}\text { Subsample of VOPD } \\
\text { patients for inter-rater } \\
\text { agreement }\end{array}$} & \multicolumn{2}{|c|}{$\begin{array}{l}\text { AVH+ children prevalence } \\
\text { study }\end{array}$} & \multicolumn{2}{|c|}{$\begin{array}{l}\text { Subsample of VOPD } \\
\text { patients for inter-rater } \\
\text { agreement }\end{array}$} \\
\hline Number & 62 & & 23 & & 347 & & 5 & \\
\hline \multirow[t]{2}{*}{$\%$ Female } & 55 & & 83 & & 49 & & 20 & \\
\hline & Mean & S.D. (Range) & Mean & S.D. (Range) & Mean & S.D. (Range) & Mean & S.D. (Range) \\
\hline Age (years) & 37.2 & $12.6(13-62)$ & 38.7 & $11.4(13-62)$ & 8.0 & $0.46(7-9)$ & 32.4 & $12.5(22-48)$ \\
\hline $\begin{array}{l}\text { Duration of AVH } \\
\text { (years) }\end{array}$ & 11.9 & $9.6(0.5-36.0)$ & 13.3 & $10.1(0.5-30.0)$ & Not assessed & 6.6 & $5.9(2.0$ & \\
\hline \multirow[t]{2}{*}{$\begin{array}{l}\text { Outcome } \\
\text { measures }\end{array}$} & \multicolumn{2}{|c|}{$\begin{array}{l}\text { Internal consistency } \\
\quad \text { (Cronbach's alpha) }\end{array}$} & \multicolumn{2}{|c|}{$\begin{array}{l}\text { Inter-rater agreement }^{\mathrm{a}} \\
\quad(\text { Cohen's kappa })\end{array}$} & \multicolumn{2}{|c|}{$\begin{array}{l}\text { Internal consistency } \\
\quad(\text { Cronbach's alpha) }\end{array}$} & \multicolumn{2}{|c|}{$\begin{array}{l}\text { Inter-rater agreement }{ }^{\mathrm{a}} \\
\text { (Cohen's kappa) }\end{array}$} \\
\hline & \multicolumn{2}{|c|}{0.84} & \multicolumn{2}{|c|}{0.84 (4 raters) } & \multicolumn{2}{|c|}{0.77} & \multicolumn{2}{|c|}{0.88 (8 raters) } \\
\hline
\end{tabular}

VOPD, voices outpatient department; $\mathrm{AVH}+$, with auditory vocal hallucinations; s.D., standard deviation.

apast month assessment.

${ }^{\mathrm{b}}$ Past year assessment.

Internal consistency was analysed using data of all available AVHRS interviews within the VOPD $(n=$ $62)$ and within the sample of 7- and 8-year-old children $(n=347)$. Measure of internal consistency used was Cronbach's alpha.

To examine face validity, all participating adult patients were questioned about the comprehensibility and comprehensiveness of the scale in a systematic way using a short questionnaire. They were asked whether all questions were clear and understandable, and whether they missed any topic.

In order to test the discriminative power of the AVHRS a severity score was composed, by counting the two most severe scores of each item, except for those on $\mathrm{HHH}$ and on localization of voices. ${ }^{1}$

\section{Results}

The inter-rater agreement scores (Cohen's kappas) were 0.84 and 0.88 , respectively, internal consistency scores (Cronbach's alpha) were 0.84 and 0.77 (Table 2).

All patients very well understood the meaning of the questions, clearly recognized the content as part of their voice hearing and they did not mention any missing topic.

Mean severity score in the patient's sample was 7.7 (s.D. 3.6; range 0-13), with women scoring slightly higher than men (8.1 v. 7.3, not significant). Patients with a diagnosis in the schizophrenic spectrum had a

\footnotetext{
${ }^{1}$ For discriminative purposes, severity indexing in the child studies (Bartels-Velthuis et al. 2011, 2012) was less rigorous.
}

significantly lower AVH severity score (mean 6.8, S.D. 3.4) than the group with other diagnoses (mean 9.7, S.D. 3.3) $(t=3.20, p=0.002)$.

Mean severity score in the children's sample was 2.1 (s.D. 1.9; range 0-10), with almost equal sores of girls and boys.

A significant difference between severity scores of patients' and children's samples was found $(t=11.9$, $p=0.000)$.

\section{Discussion}

The AVHRS showed some good psychometric properties: the inter-rater agreement can be regarded as 'excellent' (Altman, 1995) and the internal consistency as 'good' (Feinstein, 1987).

Patients had much higher severity scores than children, indicating the discriminative validity of the instrument (children being non-clinical general population participants). Speculating on the difference in AVH severity score between schizophrenic spectrum and other patients, we observed that nonschizophrenic spectrum patients were referred to the VOPD only when previous treatment had little or no effect. Therefore, the group of non-schizophrenic spectrum patients might be regarded as a selective group with more enduring severe auditory hallucinations.

In daily clinical practice, the AVHRS has proven to be a useful instrument as a starting point for therapeutic interventions, as patients indicated that they were questioned about their voices in a clear, thorough 
and recognizable way, thus adhering to therapy compliance (Cohen \& Berk, 1985). Likewise, the AVHRS was used in recommended (early) family intervention programs (Onwumere et al. 2011) in which it was shown to be an effective outcome measure (Jenner \& Van de Willige 2001; Van de Willige et al. 1996).

Some limitations are apparent. First, test-retest reliability of the AVHRS has not been examined. Test-retest analyses in the adult sample could not be performed, because in the clinical setting of the VOPD, the AVHRS assessment at intake is instantly incorporated into treatment. Thus, patients are prompted from the first contact to act upon their voices and to employ coping strategies to control them. When patients are reflecting on their voices, as a result, retest data will be contaminated with therapy instructions. Test-retest analyses in the children's sample could not be performed due to regulations of the Central Committee on Research involving Human Subjects in the Netherlands in order to avoid stigmatization. A second limitation is that, though the AVHRS has proven to measure effects of therapy effectively, sensitivity to change has not yet been assessed. Likewise, all 7-and-8-year-olds were assessed with the AVHRS. Third, generalizability of the results may perhaps be debatable. However, as the instrument showed to be suitable in two very divergent samples (chronic patients and children from the general population), it might be assumed that the AVHRS is suitable in a broad range of samples. The item scores presented in Table 1 illustrate the discriminative ability. Fourth, external validity of the scale has not yet been established. This may be a challenge for future research. Finally, a supposedly limitation of not performing factor analyses (like Haddock et al. 1999), would not add to better reliability of the scale, as in our opinion all topics of the AVHRS are important, making the outcome of the interview not reducible to a few major factors.

Strength of the study is that in the research period no 'less suitable' patients were excluded. Also, in the 5-year follow-up of the children study, the value of the severity index has proven to be useful: it was predictive for persistence of hearing voices (Bartels-Velthuis et al. 2011), higher level of severity was associated with stronger exposure to social adversity and level of severity also showed progressively stronger associations with delusions (Bartels-Velthuis et al. 2012).

Comparing the AVHRS with other instruments in this field, we consider that the MUPS (Carter et al. 1995) is a rather extensive instrument (356 items) for which empirically derived scales have not yet been developed. The revised Beliefs about Voices Questionnaire (BAVQ-R) (Chadwick et al. 2000) merely provides insight into a patient's relationship with auditory hallucinations, and does not assess form or content of the voices. We suppose that, compared with the AHS (Haddock et al. 1999), the AVHRS with more and elaborate items might improve diagnostics and treatment of hearing voices. For instance, in clinical practice, it is useful to know whether a patient is hearing several voices, requiring different coping strategies per voice. Also, hearing more than one voice was shown to be a predictor of persistence of $\mathrm{AVH}$ in the 5-year follow-up study in children (Bartels-Velthuis et al. 2011). As voices may vary in degree of anxiety elicited, it might be a straightforward treatment policy to deal with least frightening voice(s) first. Furthermore, it is important to distinguish form of address, as first person voices might be regarded as patients' own thoughts, often related to trauma or negative selfimage, which also require a specific therapeutic approach.

Considering the above and the conclusion of Ratcliff et al. (2011) that the PSYRATS (Haddock et al. 1999) might be refined and validated further, we consider that the AVHRS meets these recommendations and will be useful in identifying treatment targets beyond diagnosis (Nasrallah et al. 2011).

Copies of the AVHRS are available in English, Spanish and Dutch and can be downloaded from http://www.rgoc.nl/\#home/downloads.

\section{Acknowledgements}

Participation of the patients and children in the study is gratefully acknowledged.

\section{Conflict of Interests}

None.

A. A. Bartels-Velthuis ${ }^{1,{ }^{*}}$, G. van de Willige ${ }^{1}$, J. A. Jenner ${ }^{2}$ and D. Wiersma ${ }^{1}$

${ }^{1}$ University of Groningen, University Medical Center Groningen, University Center for Psychiatry, Groningen, The Netherlands

${ }^{2} J e n n e r$ Consultants, Haren, The Netherlands

\section{References}

Altman DG (1995). Practical Statistics for Medical Research. Chapman and Hall: London.

American Psychiatric Association (1994). Diagnostic and Statistical Manual of Mental Disorders: DSM-IV. American Psychiatric Association: Washington, DC. 
Bartels-Velthuis AA, Jenner JA, Van de Willige G, Van Os J, Wiersma D (2010). Prevalence and correlates of auditory vocal hallucinations in middle childhood. British Journal of Psychiatry 196, 41-46.

Bartels-Velthuis AA, Van de Willige G, Jenner JA, van Os J, Wiersma D (2011). Course of auditory vocal hallucinations in childhood: 5-year follow-up study. British Journal of Psychiatry 199, 296-302.

Bartels-Velthuis AA, Van de Willige G, Jenner JA, Wiersma D, Van Os J (2012). Auditory hallucinations in childhood: associations with adversity and delusional ideation. Psychological Medicine, 42, 583-593.

Carter DM, Mackinnon A, Howard S, Zeegers T, Copolov DL (1995). The development and reliability of the Mental-Health Research-Institute Unusual Perceptions Schedule (MUPS) an instrument to record auditory hallucinatory experience. Schizophrenia Research 16, 157-165.

Chadwick P, Lees S, Birchwood M (2000). The revised beliefs about voices questionnaire (BAVQ-R). British Journal of Psychiatry 177, 229-232.

Cohen CI, Berk LA (1985). Personal coping styles of schizophrenic outpatients. Hospital and Community Psychiatry 36, 407-410.

Copolov D, Trauer T, Mackinnon A (2004). On the non-significance of internal versus external auditory hallucinations. Schizophrenia Research 69, 1-6.

Feinstein AR (1987). Clinimetrics. Yale University Press: New Haven and London.

Haddock G, McCarron J, Tarrier N, Faragher EB (1999). Scales to measure dimensions of hallucinations and delusions: the psychotic symptom rating scale (PSYRATS). Psychological Medicine 29, 879-889.
Jenner JA, Van de Willige G (2001). HIT, hallucination focused integrative treatment as early intervention in psychotic adolescents with auditory hallucinations: a pilot study. Acta Psychiatrica Scandinavica 103, 148-152.

Jenner JA, Van de Willige G (2002). The Auditory Vocal Hallucination Rating Scale (AVHRS). University of Groningen, University Medical Center Groningen, University Center for Psychiatry: Groningen.

Nasrallah H, Tandon R, Keshavan M (2011). Beyond the facts in schizophrenia: closing the gaps in diagnosis, pathophysiology, and treatment. Epidemiology and Psychiatric Sciences 20, 317-327.

Onwumere J, Bebbington P, Kuipers E (2011). Family interventions in early psychosis: specificity and effectiveness. Epidemiology and Psychiatric Sciences 20, 113-119.

Popping R (1983). Measures of Agreement for Nominal Data (in Dutch). PhD Thesis, University of Groningen: Groningen.

Ratcliff K, Farhall J, Shawyer F (2011). Auditory hallucinations: a review of assessment tools. Clinical Psychology and Psychotherapy 18, 524-534.

Schneider K (1957). Primary \& secondary symptoms in schizophrenia (in German). Fortschritte der NeurologiePsychiatrie 25, 487-490.

Van de Willige G, Jenner JA, Wiersma D (1996). Effectiveness of HIT for Patients with Persistent Auditory Hallucinations [in Dutch]. University of Groningen: Groningen.

Wing JK, Babor T, Brugha T, Burke J, Cooper JE, Giel R, Jablenski A, Regier D, Sartorius N (1990). SCAN Schedules for Clinical-Assessment in Neuropsychiatry. Archives of General Psychiatry 47, 589-593. 